\title{
DOS VESTÍGIOS COLONIAIS À DESCOLONIZAÇÃO DA EDUCAÇÃO INFANTIL
}

\author{
DE LAS HUELLAS COLONIALES A LA DESCOLONIZACIÓN DE LA EDUCACIÓN \\ INFANTIL
}

\author{
FROM COLONIAL TRACES TO THE DECOLONIZATION OF EARLY CHILDHOOD \\ EDUCATION
}

Otavio Henrique FERREIRA-DA-SILVA ${ }^{1}$

RESUMO: Este ensaio objetiva analisar a influência da colonização no campo da educação infantil no Brasil, apontando para a emergência de uma pedagogia descolonizadora com as crianças e as infâncias. Identificam-se vestígios coloniais na estrutura social brasileira, no tardio sentimento para/com a infância e no ofício pedagógico. Contrapondo ao ideal da aristocracia colonial em educar as crianças pobres e filhas de escravos (subcidadãos) para serem úteis e produtivas à lavoura, entende-se que um trabalho pedagógico descolonizador com as crianças na educação infantil irá educá-las para a cidadania de direitos, invencionática e de ressignificação do mundo, para que elas possam amar e respeitar todos os povos, caminhando rumo à construção de um mundo fraterno e feliz.

PALAVRAS-CHAVE: Pedagogia descolonizadora. Educação infantil. Invencionática.

RESUMEN: Este ensayo se propone analizar la influencia de la colonización en el campo de la educación de la primera infancia en Brasil, señalando el surgimiento de una pedagogía descolonizadora con los niños y la infancia. Identifica las huellas coloniales en la estructura social brasileña, en el sentimiento tardio hacia la infancia y en el oficio pedagógico. En oposición al ideal de la aristocracia colonial de educar a los niños pobres y a las hijas de los esclavos (subciudadanos) para que sean útiles y productivos para la plantación, se entiende que un trabajo pedagógico descolonizador con los niños en la educación infantil los educará para la ciudadanía de derechos, la invención y la resignificación del mundo, para que puedan amar y respetar a todos los pueblos, caminando hacia la construcción de un mundo fraterno y feliz.

PALABRAS CLAVE: Pedagogía descolonizadora. Educación infantil. Invencionista.

ABSTRACT: This essay aims to analyze the influence of colonization in the field of early childhood education in Brazil, pointing to the emergence of a decolonizing pedagogy with children and childhood. It identifies colonial traces in the Brazilian social structure, in the late feeling towards childhood and in the pedagogical craft. In contrast to the ideal of the colonial aristocracy in educating poor children and daughters of slaves (sub-citizens) to be useful and productive for farming, it is understood that a decolonizing pedagogical work with

${ }^{1}$ Universidade Federal de Minas Gerais (UFMG), Belo Horizonte - MG - Brasil. Doutorando em Educação. ORCID: https://orcid.org/0000-0002-2754-4783.E-mail: hotaferreira@gmail.com 
children in early childhood education will educate them for citizenship of rights, of invention and technology, and of resignification of the world, so that they can love and respect all people, moving towards the construction of a fraternal and happy world.

KEYWORDS: Decolonizing Pedagogy. Early childhood education. Inventionist.

\section{Introdução}

Pensar em educação infantil e cidadania em um país como o Brasil é diferente de pensar em qualquer outro país do mundo. Aqui há uma mistura estranha de riquezas e desigualdade social. É o maior país da América do Sul, uma das maiores potências econômicas e de produção de conhecimento científico do mundo ${ }^{2}$. No entanto, é um país extremamente pobre, carrega em sua composição social a raiz escravocrata, sendo o maior país negro fora do continente africano ${ }^{3}$, e é um dos estados nacionais em que mais se mata mulheres no mundo, cerca de três por $\operatorname{dia}^{4}$.

No Brasil as desigualdades sociais são assustadoras. Conforme alerta o sociólogo Jessé de Souza (2003), há uma crença disseminada no "imaginário social dominante" do país sobre os brasileiros serem todos iguais, evidenciada em jargões no estilo de "somos todos brasileiros" ou de "Noventa milhões em ação, pra frente Brasil do meu coração". Essa crença também alimenta que as desigualdades que existem entre os brasileiros são apenas em relação à renda que recebem, contribuindo para o pensamento de que somente o progresso econômico poderia resolver esse problema. Porém, ao realizar uma análise histórica, é possível observar que o Brasil foi o país “[...] de maior crescimento econômico do globo entre 1930 e 1980, sem que as taxas de desigualdade, marginalização e subcidadania jamais fossem alteradas radicalmente, [o que] deveria ser um indicativo mais do que evidente do engano dessa pressuposição" (SOUZA, 2003, p.51).

É nesta terra pós-moderna estranha, rica e desigual, com imensa diversidade de povos e etnias, e ainda assim, racista, que surgiu no século XVI as escolas primárias e no final do século XIX as primeiras instituições de educação infantil ${ }^{5}$. Desse modo, é sob um viés colonial de pessoas estranhas que esta terra foi violentada, e em que foram transformados em

${ }^{2}$ Mais informações em: https://www.nsf.gov/statistics/2018/nsb20181/tables/tt05-22. Acesso em: 15 abr. 2020.

${ }^{3}$ Mais informações em: https://www.cadaminuto.com.br/noticia/312329/2017/11/05/brasil-e-o-pais-com-maiorpopulacao-negra-fora-da-africa. Acesso em: 15 abr. 2020.

4 Ver mais em: https:/catracalivre.com.br/cidadania/brasil-registra-um-caso-de-feminicidio-a-cada-7-horas/. Acesso: 15 abr. 2020.

${ }^{5}$ As primeiras instituições foram jardins de infância, uma ideia importada da Europa, terra do colonizador. O público deste atendimento não era as crianças filhas de escravos e pobres. Estas serão atendidas nas creches em tempos mais tardios, já no século XX. 
objetos e mercadorias os povos que aqui já estavam, obrigando-os a entregar-lhes sua força de trabalho, seu corpo, sua mente e a sua fé. Algum tempo depois, esses colonizadores tornaramse reis, acumularam riquezas e usaram da caridade como forma de contenção social. Proporcionaram, então que crianças e jovens fossem educados na perspectiva que bem entendessem, fazendo-os não desejar outro status social que não fosse o da servidão (LEWIS, 2019). Esse é um dos motivos que evidencia a urgência e a necessidade de uma educação descolonizadora ser implementada a partir da infância no Brasil.

Este artigo, então, de perspectiva ensaística, tem como objetivo analisar a influência da colonização no campo da educação infantil no Brasil, apontando para a emergência de uma pedagogia descolonizadora com as crianças e as infâncias. Para tanto, será discutido, brevemente, questões como: a herança colonial e as crianças na história do país, a luta por creches como luta pelo direito à educação das crianças negras e periféricas, as raízes coloniais no ofício do pedagogo e caminhos para a descolonização da educação infantil rumo à cultura da invencionática (BARROS, 2008; ABRAMOWICZ; OLIVEIRA, 2012).

\section{A herança colonial e as crianças no Brasil}

No livro, "História das crianças no Brasil", Priore (2018) afirma que há uma tardia sensibilidade com a infância no Brasil, relacionada com a herança colonial deixada na cultura desta sociedade onde não houve tanto espaço para que um sentimento afetivo florescesse. A autora pontua, ainda, que a evidência deste tardio sentimento foi: a ausência "de um sistema econômico que exigisse a adequação física e mental dos indivíduos a esta nova realidade, não foram implementados os instrumentos que permitiriam a adaptação a este novo cenário" (PRIORE, 2018, p. 10). Exemplo disso é que somente em 2014, em pleno século XXI, passou-se a ter uma séria preocupação do Estado brasileiro em relação ao trato das famílias brasileiras com as crianças, o que ficou explícito na aprovação da Lei no 13.010/2014, Lei da Palmada, que diz em seu Artigo 18-A: "A criança e o adolescente têm o direito de ser educados e cuidados sem o uso de castigo físico ou de tratamento cruel ou degradante, como formas de correção, disciplina, educação ou qualquer outro pretexto, pelos pais, pelos integrantes da família ampliada [...]” (BRASIL, 2015, p. 12).

O papel da escola é compreendido hoje como fundamental para construir na relação com as famílias novos olhares sobre as potencialidades das crianças e do desenvolvimento humano delas. Mas desde os tempos coloniais as escolas jesuítas foram direcionadas para poucas pessoas e, mesmo quando o ensino público foi minimamente instalado no Brasil, entre 
os séculos XVIII e XIX, já havia a concepção de que "[...] a alternativa para os filhos dos pobres não seria a educação, mas sua transformação em cidadãos úteis e produtivos na lavoura, enquanto os filhos de uma pequena elite eram ensinados por professores particulares" (PRIORE, 2018, p.10).

A criança no Brasil passou a receber mais atenção da família em tempos mais recentes, visto que essa mudança acompanha, também, os desdobramentos do que a sociedade e o Estado fizeram em prol dela. Foi a partir da Constituição de 1988 e da aprovação do Estatuto das Crianças e dos Adolescentes de 1990 que as crianças passaram a ser reconhecidas como sujeitos históricos de direitos. Mesmo assim, esse reconhecimento não aconteceu de forma sincronizada em todas as famílias e comunidades brasileiras.

A infância popular sempre esteve mais vulnerável ao trato familiar, já que o trabalho infantil é uma marca de grande parte da população brasileira, a qual até a década de 1970 ainda era em sua maioria rural. Muitas crianças das famílias camponesas trabalhavam junto de suas famílias na agricultura, por exemplo. Com a mecanização da produção do campo e expansão da especulação imobiliária na zona rural por parte dos latifundiários, muitas famílias acabaram migrando para as grandes cidades entre os anos de 1970 a 1980 em busca de trabalho nas indústrias urbanas (FERREIRA-DA-SILVA, 2016).

Essa mudança territorial não necessariamente provocou uma mudança de concepção das famílias populares, no que diz respeito à infância de suas crianças. E passando a habitar as metrópoles, várias formas de opressão surgiram e marcaram a rotina da vida desses migrantes, como por exemplo, os problemas de infraestrutura das grandes cidades, a falta de moradia e saneamento básico, superlotação do sistema de saúde e insuficiência de políticas públicas de creches, dentre outros.

\section{Lutar por creche, lutar pela cidadania: direito à educação das crianças negras e periféricas}

Após a abolição da escravatura as mulheres e homens libertos continuaram presos às amarras dos seus "ex-senhores", sujeitando-se à realização de trabalhos pesados a troco de muito pouco dinheiro e comida. Na medida em que a industrialização avançou no país, mulheres negras que conseguiram adentrar no mercado industrial passaram a vender a sua força de trabalho a condições drasticamente inferiores se comparadas aos ganhos masculinos (LEWIS, 2019). 
No caso das mulheres negras, por conta de atividades exercidas fora do ambiente doméstico como empregadas domésticas, trabalhadoras de indústria, prostitutas, dentre outras, foi que ao longo do século XX surgiram as primeiras creches para as crianças das vilas e favelas dos subúrbios brasileiros. As mulheres se organizavam na luta pela sobrevivência delas e dos filhos, entre aquelas que cuidavam e educavam as crianças e aquelas que trabalhariam fora de casa para arranjarem o sustento de suas famílias ${ }^{6}$.

Diante de um contexto de Estado burocrático de direito ${ }^{7}$ no Brasil, da ausência de políticas voltadas ao atendimento das crianças periféricas e no amparo às mães trabalhadoras, é que surgem movimentos sociais como o Movimento de Luta Pró-Creches (MLPC). Esse movimento social se originou nas periferias da divisa entre Belo Horizonte e Contagem, Minas Gerais, no ano 1979. O MLPC foi um instrumento de mobilização popular liderado por mulheres pioneiras das creches comunitárias na região da divisa, que passaram a lutar pelo direito das crianças ao acesso à educação e assistência com qualidade ${ }^{8}$ :

Tratava-se de iniciativas de mulheres habitando bairros pobres, que a princípio contavam apenas com o apoio dos vizinhos, das mães das crianças e, às vezes, do padre da paróquia mais próxima. As primeiras creches foram o embrião do que mais tarde se tornaria o Movimento de luta por Creches. Elas começaram a se reunir para trocar informações e experiências e buscar soluções para as suas dificuldades (FILGUEIRAS, 1994, p. 19).

A luta por reconhecer as creches como responsabilidade do Estado esteve em grande efervescência no Brasil durante o período de 1960 a 1980. Essa luta foi acampada pelo movimento de mulheres, pelo movimento negro ${ }^{9}$ e pesquisadoras da área da infância, juntamente a outros movimentos da sociedade civil. Por conta disso, foi conquistado o direito de acesso das crianças de 0 a 5 anos à educação institucionalizada, a partir da aprovação da

${ }^{6}$ Ferreira-da-Silva (2020) apresenta uma análise ampliada da origem dessas instituições, desde a chegada dos
primeiros jardins de infância no Rio de Janeiro e São Paulo na primeira década do período republicano
brasileiro, bem como das primeiras intervenções do Governo Federal para o setor, do período de reconhecimento
da educação infantil como direito da criança e do período após aprovação das Lei de Diretrizes e Bases da
Educação (LDB) de 1996 .
7 Sobre o Estado burocrático de direito, Lewis (2019) diz: "Essa violência perdurou, no Brasil, no período
colonial, no período do império e no período republicano. Para isso, as classes favorecidas fundaram um estado
burocrático de direito, com suas instituições políticas, jurídicas, policiais e militares, cujas autoridades
perpetuaram e perpetuam narrativas e discursos colonialistas, importados de metrópoles do passado e do
presente, como se o país, chamado Brasil, devesse se perpetuar eternamente como uma colônia serviçal do
imperialismo internacional" (LEWIS, 2019, p. 8-9).
${ }^{8}$ Filgueiras (1994) diz que em um período de 12 anos o MLPC sofreu mudanças em sua concepção, passando da
defesa da manutenção das creches comunitárias para a luta política pelo direito à Educação Infantil.
9 No Brasil, com o surgimento do Movimento Negro na década de 1940, verifica-se um intenso processo de
organização para colocar na agenda pública as desigualdades raciais e sociais vivenciadas pelo povo negro. Toda
movimentação do Movimento de homens e mulheres negras terá, também, grande ápice de mobilização durante
a construção do texto da Constituição de 1988, que abrirá “[...] agenda de ações para o ativismo negro, cujas
demandas se voltaram para as ações de implementação de políticas direcionadas para a população negra"
(HEILBORN; ARAÚJO; BARRETO, 2010, p. 215). 
Constituição Cidadã, em 1988. Diante desses fatos, pode-se considerar que a educação infantil e seu reconhecimento como primeira etapa da educação básica no Brasil nasceu de um processo de luta por direitos, liderado por grupos identitários que durante 488 anos (15001988) ${ }^{10}$ viveram em condição de subcidadania e de exclusão socioeconômica, cultural e política.

Foi, então, após quase cinco séculos da chegada do Império português no Brasil que o povo brasileiro legitimou uma Constituição que contemplou especificidades próximas do que é a real composição social dessa nação que apresenta, ao mesmo tempo, desigualdades sociais e uma diversidade no que diz respeito à idade, cor, raça, cultura, religião, gênero e política. Inaugurou-se com esta Carta Magna uma estrutura de proteção aos direitos humanos no Brasil, onde todos os indivíduos a partir da primeira infância têm o direito à proteção do Estado. O Estado também tem o dever de não violentar moral e fisicamente qualquer que seja o cidadão, tendo em vista que essa é uma prática que ainda ocorre com os indivíduos que vivem à margem da sociedade.

\section{O pedagogo e a colonização}

As mudanças em relação ao tratamento da infância no Brasil aconteceram tardiamente e foram influenciadas pelo pensamento da Idade Moderna ${ }^{11}$. É na modernidade que no mundo ocidental o discurso pedagógico assumiu a " [...] especificidade psicológica e a função social da infância como seu núcleo. No campo da pedagogia, a criança converteu-se no sujeito educativo por excelência", já que a infância passou a ser vista com características diferentes da idade adulta (CUSTÓDIO, 2019, p.80).

A origem do sujeito responsável pela educação formal das crianças da primeira infância vem do mundo grego. O pedagogo era um escravo encarregado da condução da criança de elite até o mestre responsável por ensiná-la, tendo como objetivo guiá-la e protegêla de imprevistos ao longo do caminho. Seu ofício era desenvolvido até o momento em que a criança se tornava adolescente (CUSTÓDIO, 2019). Desde esse período, a ênfase do trabalho do pedagogo era fundamentada em perspectiva educativa e, à medida que mudanças no cenário da educação aconteceram, novas funções foram sendo atribuídas a este escravo. A

${ }^{10}$ Destaca-se que mesmo após a abolição da escravatura "[...] a sociedade brasileira independente continuou excludente e violenta com relação à maioria da população. Os escravos libertos em 1888 foram lançados na marginalidade" (LEWIS, 2019, p. 28).

${ }^{11}$ No mundo ocidental o novo sentimento em relação à infância influenciou a publicação de documentos oficiais em defesa e proteção das crianças como a Declaração Universal dos Direitos das Crianças (1959) e Convenção Internacional sobre os Direitos da Criança (1989).

RPGE- Revista on line de Política e Gestão Educacional v. 25, n. 1, p. 311-325, jan./abr. 2021 e-ISSN:1519-9029. 
partir do instante que o conhecimento escolarizado adentrava na vida das crianças que tinham acesso a esse tipo de educação, eram requeridos profissionais capacitados e, portanto, outros sujeitos acabaram por exercer trabalho.

O campo da pedagogia detém um discurso amplamente normativo e prescritivo desde suas origens no trabalho do escravo (pedagogo), como por exemplo, o de condução, direcionamento e ordenamento da criança. Este discurso, embora esteja relacionado com o trabalho do pedagogo até os dias atuais, não é produzido apenas por esses profissionais, mas por uma série de interessados que veem no processo educativo a oportunidade de moldar, desde a infância, os comportamentos dos indivíduos recém chegados ao mundo. Esse tipo de conduta normativa, direcionada e ordenada afeta a vida das crianças e o trabalho do professor, bem como a escola como um todo (CUSTÓDIO, 2019).

Há uma forte herança colonial de origem escravocrata na formação atual das pedagogas no Brasil que está inconscientemente introjetada na mente destas profissionais da educação infantil e do ensino fundamental. E devido a esse passado marginalizado da função de pedagoga, não é de se estranhar que as professoras da educação infantil no Brasil recebam os menores salários e possuam condições de trabalho precarizadas.

É importante considerar que foram feitas mudanças necessárias no currículo de formação no curso de Pedagogia, como: a inclusão de disciplinas sobre as relações étnicoraciais no advento das leis 10.639/2003 e 11.645/2008 (BRASIL, 2003; 2008a); novas diretrizes curriculares para o Curso de Licenciatura em Pedagogia no ano de 2006 (BRASIL, 2006), quando passa-se a valorizar na formação o campo da educação infantil; e a implementação do Piso Salarial Nacional para os Profissionais do Magistério com a aprovação da Lei 11.738/2008 (BRASIL, 2008). Porém, ressalta-se que mesmo com essas medidas legais, ainda não se foi possível acabar com a herança colonial presente no campo da pedagogia no Brasil.

A compreensão dos diferentes sentidos de educação presentes na sociedade e o impacto que geram nas vidas dos indivíduos, principalmente, das crianças de 0 a 5 anos, ressalta a importância de as instituições escolares se comprometerem com a construção de uma educação descolonizadora e voltada para a cidadania. Não estou me referindo a uma cidadania direcionada para o mercado de trabalho e/ou servidão, pois esta tem raízes escravocratas e é uma condição de subcidadania (SOUZA, 2003; BUFFA, 2007). Refiro-me a uma cidadania verdadeiramente democrática e voltada para os direitos sociais, conforme ressaltado por Noguera-Ramírez (2019, p. 57): “O pensamento político situa o assunto educativo em termos da democracia, ou seja, do Estado e do indivíduo e seus direitos; a 
economia situa o assunto educativo em termos de competitividade, ou seja, em termos de mercado e de individualização".

No que diz respeito à educação das crianças, tanto no âmbito institucional quanto no informal há uma constante disputa de narrativas. Por isso, se na origem colonizadora da educação os povos que não tinham cidadania reconhecida socialmente como, os escravizados e os nativos de determinadas regiões, por exemplo, os indígenas no Brasil, foram cristianizados por seus colonizadores para que se tornassem "dóceis", domesticados e vivessem na pobreza (LEWIS, 2019) - na educação em tempos pós-modernos e com a emergência do reconhecimento das especificidades das crianças, a educação escolar não pode abrir mão dessa disputa com o mercado e a prosperidade. É preciso fazer jus à especificidade histórica conquistada pelas crianças que é serem educadas enquanto sujeito de direitos, estando verdadeiramente incluídas na vida democrática.

\section{Descolonizar a educação infantil: a caminho da invencionática}

Uso a palavra para compor meus silêncios.

Não gosto das palavras fatigadas de informar. Dou mais respeito às que vivem de barriga no chão tipo água pedra sapo.

Entendo bem o sotaque das águas. Dou respeito às coisas desimportantes e aos seres desimportantes. Prezo insetos mais que aviões. Prezo a velocidade das tartarugas mais que a dos mísseis. Tenho em mim esse atraso de nascença.

Eu fui aparelhado para gostar de passarinhos.

Tenho abundância de ser feliz por isso. Meu quintal é maior do que o mundo. Sou um apanhador de desperdícios: Amo os restos como as boas moscas. Queria que a minha voz tivesse um formato de canto. Porque eu não sou da informática: eu sou da invencionática. Só uso a palavra para compor meus silêncios (BARROS, 2008, p.45).

Para pensar pedagogias da educação infantil que não estejam sob o viés colonizador é preciso refinar os olhos para compreender as crianças, como nos mostra Manoel de Barros (2008). O poeta nos ajuda a pensar que a singularidade da criança é produzir experiências sobre aquilo que vive, o que sente e pensa. Quando a criança se expressa sobre o mundo com 
as suas invenções, ela está assumindo o protagonismo do pensar e, assim, contrariando a lógica econômica que padroniza o funcionamento do mundo e faz com que muitas pessoas acreditem que gostar dos passarinhos, entender a linguagem das águas dos rios e da chuva são atividades menos relevantes. Essa grande massa também vai ser educada para valorizar, sob a ótica do capital, que o importante é mesmo valorizar as "palavras fatigadas de informar". Contrariar a lógica colonial e mortífera ao mundo do capitalismo requer aprender qual é o sentido de infância na era moderna, sua singularidade de inventar e de ser da invencionática. Nesse sentido, é importante considerar que a composição do verbo "inventar" está situada num movimento interno de dentro para fora, e não ao contrário, que é o que faz a educação colonizadora.

A sociologia da infância tem contribuído para entender melhor as diferentes experiências de infância das crianças. No caso do Brasil, essas diferenças estão presentes nas desigualdades sociais que atravessam essa etapa inicial da vida das pessoas, conforme apontado ao longo das reflexões deste trabalho. O campo de estudos e pesquisas da sociologia da infância é responsável por desenvolver conceitos como: “[...] Protagonismo infantil, processos de socialização, estrutura social, infância/criança, autoria social/agência, cultura infantil, geração, etnografia, cultura de pares [...]” (ABRAMOWICZ, 2018, p. 375). Estes conceitos têm contribuído para que pesquisadores e educadores passem a projetar novos olhares e criem novas abordagens e análises quanto às relações que as crianças estabelecem com outras crianças e com os adultos. Além disso, a sociologia da infância tem resgatado um movimento de dar voz às crianças, contrariando o adultocentrismo ${ }^{12}$ e o colonialismo presente na educação, onde já se sabe previamente que “[...] são os adultos quem falam das/sobre as crianças e que isto faz parte de uma das linhas do processo que chamamos de socialização" (ABRAMOWICZ, 2018, p.375).

A socialização das crianças sob lógicas adultocentradas e colonizadoras tende a castrar a curiosidade delas, retirando seu protagonismo no ato de conhecer e do fazer pedagógico. E ainda, as crianças são educadas com base em uma perspectiva eurocêntrica, que desconsidera os preconceitos étnico-culturais presentes nos meios sociais e herdados do longo processo de colonização vivido no Brasil. Assim, compreender as relações micropolíticas que acontecem

12 Sobre o conceito de adultocentrismo, concordo com a definição de Santiago e Faria (2015, p.73), que sustentam: "O adultocentrismo é um dos preconceitos mais naturalizados pela sociedade contemporânea. Ele atribui capacidades e fazeres às crianças para que se tornem adultas no futuro, desconsiderando os aspectos singulares da própria infância, tornando esse momento da vida apenas uma passagem, apenas um vir a ser, em que aprendemos a nos relacionar e a nos integrar à sociedade. [...] A infância, na perspectiva adultocêntrica, é somente um período de transição e de aquisição dos elementos simbólicos presentes na sociedade, tendo a criança, assim, uma condição de ser menor, ser inferior, lugar que lhe é dado pelo grupo dominante correspondente: os adultos e as adultas" (SANTIAGO, FARIA, 2015, p.73). 
na educação infantil brasileira em tempos pós-modernos exige a apreensão das relações sociais em sua perspectiva interseccional como raça, gênero e classe.

As infâncias das crianças brasileiras são bem diferentes das infâncias vividas em países colonizadores. Como ressaltam Abramowicz e Oliveira (2012), estudos como o de Jens Qvotrup sobre a infância como categorial estrutural permanente, enfatizam a análise das crianças por meio de uma perspectiva geracional, sem considerar a questão racial. No caso do Brasil a situação é outra, já que a desigualdade social perpassa, sobretudo, por questões raciais, de gênero e classe social e, por isso, é preciso considerar "[...] a diversidade enquanto fator que divide o entendimento sobre a criança e oculta a perspectiva geracional, pois nos leva a discutir políticas de identidade e não a desenvolver estudos sobre a criança enquanto coletividade, ou seja, considerando o status comum entre as crianças" (ABRAMOWICZ; OLIVEIRA, 2012, p. 52). Também, a “[...] pobreza impacta a criança negra de maneira mais cruel e contundente do que a criança pobre e branca, já que a família negra vive com mais intensidade a desigualdade social. Mas não é só isso, a pobreza é atravessada pela raça, o que significa dizer que a raça é também explicativa da pobreza" (ABRAMOWICZ; OLIVEIRA, 2012, p. 50).

A partir de uma leitura sociológica sobre a condição da infância no Brasil, pode-se afirmar que não há uma única infância, ou seja, as condições de desenvolvimento humano não são iguais para todas as crianças brasileiras. Para oportunizar condições de igualdades nos direitos sociais a todas as crianças, é preciso considerar que existem diferenças entre elas. Por isso, uma pedagogia que for compreendia como própria para as crianças da educação infantil não pode ser projetada da mesma para a criança que mora no Itaim Bibi, bairro nobre de São Paulo com "Muito Elevado" Índice de Desenvolvimento Humano (IDH), e para a que mora no Morro do Alemão, bairro popular com o menor IDH da cidade do Rio de Janeiro. Também, essa pedagogia não pode ser defendida como a mesma para as crianças que moram em reservas indígenas e para as que moram em Nova Lima (maior IDH de Minas Gerais). Muito menos a mesma para as crianças da Noruega e para as que estudam nos centros infantis municipais (CIM's) da cidade de Betim/MG onde $89,84 \%$ da população da cidade (FERREIRA-DA-SILVA, 2016) tem renda familiar de até três salários mínimos e moram em bairros populares carentes de infraestrutura básica. Uma pedagogia que se diz igual para todas as crianças, mas nega as desigualdades socioculturais, étnicas e econômicas, acaba se tornando excludente.

No Brasil, a criança negra tem em sua origem familiar uma descendência escravocrata e enfrenta de forma mais letal a perversidade da estrutura social de dominação masculina que 
tende a favorecer homens brancos (BOURDIEU, 2002). Tais aspectos prejudicam profundamente a possibilidade de estabilidade social e profissional de suas respectivas mães. Há, ainda, o fato de muitas dessas crianças terem pouco ou nenhum contato com seus pais, tendo em vista que, no Brasil, $75 \%$ das vítimas anuais de homicídios são de jovens negros ${ }^{13}$.

A educação no Brasil precisa pensar em práticas pedagógicas que minimizem e acabem com a opressão infantil, principalmente de crianças negras que vivem em situação de marginalidade. Estas crianças não podem mais ser percebidas na escola exclusivamente por “[...] problemas de relacionamento com seus colegas e professores ocasionados pela cor, gerando uma relação conflituosa e, muitas vezes, nociva para aqueles que acabam sendo rejeitados por seus atributos físicos", isto desde a educação infantil (ABRAMOWICZ; OLIVEIRA, 2012, p. 54).

Colocar as crianças de 0 a 5 anos no centro do planejamento das políticas públicas e do currículo de formação de professores é uma perspectiva influenciada pela sociologia da infância. Nessa direção, reafirma-se o protagonismo que a criança precisa ocupar em uma pedagogia da educação infantil que realmente esteja comprometida com a superação das marginalidades dos povos do mundo. Garantir o direito de "[...] fala da criança é uma inversão nos processos de subalternização, é um movimento político [...]” (ABRAMOWICZ, 2018, p. 376).

Mesmo que não haja "[...] algo na fala das crianças que seja excepcional ou diferente (apesar de que pode casualmente até haver), mas, a criança ao falar faz uma inversão hierárquica discursiva que faz falar aquelas cujas falas não são levadas em conta, não são consideradas" (ABRAMOWICZ, 2018, p. 376). Por haver crianças que nem sempre são consideradas nas práticas pedagógicas generalistas quanto à compreensão de infância, uma pedagogia que queira dar voz a todas elas somente será possível se for pautada pelas diferenças (equidade).

Na educação das crianças de 0 a 5 anos para a cidadania não basta apenas romper com o adultocentrismo. É preciso romper, também, com o colonialismo presente no fazer pedagógico. Dar voz às crianças pode romper com o adultocentrismo, mas caso a professora ignore os estereótipos culturais presentes nas relações entre as crianças não haverá rompimento verdadeiro com as marcas colonizadoras existentes na sociedade brasileira. Portanto, é necessário que diversas situações rotineiras sejam desnaturalizadas e superadas,

13 Para mais informações ver: https://brasil.estadao.com.br/noticias/geral,75-das-vitimas-de-homicidio-no-paissao-negras-aponta-atlas-da-violencia,70002856665. Acesso em: 17 abr. 2020. 
como por exemplo, quando duas meninas brincam de casinha e a criança branca é a patroa e a negra é a babá.

A pedagogia da educação infantil precisa estar atenta às marcas segregacionistas e não pode se tornar uma licensiosidade ${ }^{14}$ diante das discriminações que crianças negras vivem na própria cultura de pares. Apenas dar voz às crianças e não fazer intervenções eticamente necessárias frente às discriminações está mais voltado para uma ressignificação do darwinismo social na perspectiva da infância, onde as crianças mais "aptas" e "fortes" sobrevivem e dominam as demais ${ }^{15}$, do que para uma pedagogia capaz de formar cidadãos comprometidos com a superação das marginalidades sociais. Por isso, apesar dos imensos avanços trazidos pelas leis 10639/2003 e 11645/2008, há um equívoco no que diz respeito à orientação de que "História e Cultura Afrobrasileira e Indígena" seja ministrada apenas nos currículos do ensino fundamental e médio, excluindo, assim, a educação infantil ${ }^{16}$. O trabalho desta temática não pode estar ausente de uma pedagogia da educação infantil comprometida com a superação do adultocetrismo e colonialismo.

Para educar crianças numa perspectiva descolonizadora é preciso ir além do que as pedagogias fizeram até hoje. Necessita-se de novas possibilidades de

[...] socialização para a produção de novas crianças e outras infâncias, no sentido de pensar outra forma de educação com crianças pequenas, que podem ser informadas a partir de uma sociologia da infância que aborde aspectos de nossa realidade social, cultural, econômica e, sobretudo, racial (ABRAMOWICZ; OLIVEIRA, 2012, p.62).

Educar as crianças da educação infantil para a cidadania requer fazer uso de uma educação descolonizadora, de pedagogias descolonizadoras e de métodos que possibilitem à professora, primeiramente, se reconhecer como um sujeito implicado em um contexto micropolítico. Dessa forma, sua prática pedagógica estará

fortemente empenhada em entender o que as crianças falam, o que querem conhecer, o que há de interessante a fazer e a deixar de fazer, a estudar, deixar para lá; pensar o que há de interessante para visitar, que novas formas de brincar podem ser brincadas, que músicas e que danças podem ser inventadas (ABRAMOWICZ; OLIVEIRA, 2012, p. 62).

${ }^{14}$ Sobre o conceito de licenciosidade, Freire (2019, p. 102) diz: "Licencioso teria sido se tivesse permitido que a indisciplina de uma liberdade mal centrada desequilibrasse o contexto pedagógico, prejudicando assim o seu funcionamento".

${ }^{15}$ Para ver mais sobre o darwinismo social consultar os estudos de Heilborn, Araújo e Barreto (2010).

${ }^{16}$ Conforme a Lei 10639/2003: "Nos estabelecimentos de ensino fundamental e médio, oficiais e particulares, torna-se obrigatório o ensino sobre História e Cultura Afro-Brasileira". (BRASIL, 2003, s/p). E conforme a Lei 11645/2008: "Nos estabelecimentos de ensino fundamental e de ensino médio, públicos e privados, torna-se obrigatório o estudo da história e cultura afro-brasileira e indígena" (BRASIL, 2008, s/p)

RPGE- Revista on line de Política e Gestão Educacional v. 25, n. 1, p. 311-325, jan./abr. 2021. e-ISSN:1519-9029. 


\section{Considerações finais}

Cientes dos limites que temos diante da magnitude do tema proposto neste trabalho, buscou-se colocar em discussão os vestígios coloniais presentes na infância e na educação infantil no Brasil. Diante da drástica desigualdade social, econômica, racial e de gênero dos brasileiros, entende-se que alcançar uma educação infantil com qualidade e inclusão social só será possível por meio da implementação de políticas públicas que partam da perspectiva da descolonização pedagógica.

Há uma tardia sensibilização no que diz respeito às questões referentes às crianças de 0 a 5 anos no Brasil, acentuando-se mais ainda, em relação às crianças negras e periféricas. Estas foram reconhecidas como sujeitos de direitos somente após 488 de exclusão social que continuou mesmo após a abolição da escravatura em 1888. A consolidação de uma legislação de amparo e proteção com garantia de direitos também às crianças negras e periféricas, que aconteceu entre as décadas de 1980 e 1990, só foi possível por meio da luta social liderada por mulheres negras e periféricas, como as integrantes do Movimento de luta Pró-Creche das periferias metropolitanas de Belo Horizonte/MG.

Diante dos vestígios coloniais no ofício do pedagogo, sendo que muitos ainda persistem como a desvalorização da função e os discursos de normatividade, de moldar, de direcionar e de ordenar, para inclusão das crianças e infâncias em um Estado democrático, é preciso disputar o discurso da educação com uma pedagogia descolonizadora e no caminho da invencionática.

Esta pedagogia, construída junto das crianças, irá apanhar os desperdícios do mundo para o repensar e o ressignificar, mostrando o caminho de amar os restos, os povos marginalizados e os excluídos da terra. Desde a mais tenra idade as crianças serão ensinadas que para alcançarmos um mundo mais justo e amoroso necessita-se dar respeito às coisas desimportantes e aos seres desimportantes.

Assim, pedagogos e pedagogas e professores e professoras não mais educarão crianças e jovens para serem úteis e produtivos à lavoura, mas cidadãos de direitos e deveres, que têm direito à cidade, a caminhar nas ruas com tranquilidade e a viver com felicidade.

AGRADECIMENTOS: Agradeço imensamente ao meu orientador Prof. Dr. Ademilson de Sousa Soares, à Universidade Federal de Minas Gerais pela oportunidade de realizar esta pesquisa e à CAPES pelo financiamento. 


\section{REFERÊNCIAS}

ABRAMOWICZ, Anete. Sociologia da Infância: traçando algumas linhas. Contemporânea. São Carlos, v.8, n.2, p.371-383, jul-dez. 2018.

ABRAMOWICZ, Anete; OLIVEIRA, Fabiana. As relações étnico-raciais e a sociologia da infância no Brasil: alguns aportes. In: BENTO, Maria Aparecida Silva. Educação infantil, igualdade racial e diversidade: aspectos políticos, jurídicos, conceituais. São Paulo: CEERT, 2012, 221p.

BARROS, Manoel. Memórias inventadas: as infâncias de Manoel de Barros. São Paulo: Planeta, 2008, 157p.

BOURDIEU, Pierre. A dominação masculina. 2. ed. Rio de Janeiro: Bertrand Brasil, 2002, $160 \mathrm{pp}$.

BRASIL. Lei $\mathbf{n}^{0}$ 10.639, de 9 de janeiro de 2003: Altera a Lei $\mathrm{n}^{\circ} 9.394$, de 20 de dezembro de 1996, que estabelece as diretrizes e bases da educação nacional, para incluir no currículo oficial da Rede de Ensino a obrigatoriedade da temática "História e Cultura Afro-Brasileira", e dá outras providências. Brasília, 2003. Disponível em: http://www.planalto.gov.br/ccivil_03/leis/2003/110.639.htm. Acesso em: 08 jun. 2020.

BRASIL. Resolução CNE/CP n⿳10 1, de 15 de maio de 2006: Institui Diretrizes Curriculares Nacionais para o Curso de Graduação em Pedagogia, licenciatura. Brasília: Conselho Nacional de Educação, 2006. Disponível em: A http://portal.mec.gov.br/cne/arquivos/pdf/rcp01_06.pdf. Acesso em: 08 jun. 2020.

BRASIL. Lei $\mathbf{n}^{\mathbf{0}}$ 11.645, de 10 março de 2008: Altera a Lei $\mathrm{n}^{\circ}$ 9.394, de 20 de dezembro de 1996, modificada pela Lei $\mathrm{n}^{\circ} 10.639$, de 9 de janeiro de 2003, que estabelece as diretrizes e bases da educação nacional, para incluir no currículo oficial da rede de ensino a obrigatoriedade da temática "História e Cultura Afro-Brasileira e Indígena". Brasília, 2008a. Disponível em: http://www.planalto.gov.br/ccivil_03/_Ato2007-2010/2008/Lei/L11645.htm. Acesso em: 08 jun. 2020.

BRASIL. Lei $\mathbf{n}^{\mathbf{0}}$ 11.738, de 16 de julho de 2008: Regulamenta a alínea "e" do inciso III do caput do art. 60 do Ato das Disposições Constitucionais Transitórias, para instituir o piso salarial profissional nacional para os profissionais do magistério público da educação básica. Brasília, 2008b. Disponível em: http://www.planalto.gov.br/ccivil_03/_ato20072010/2008/lei/111738.htm. Acesso em: 16 jul. 2020.

BRASIL. Estatuto da criança e do adolescente. 13. ed. Brasília: Edições Câmara, 2015, $116 \mathrm{p}$.

BUFFA, Ester. Educação e cidadania burguesas. In: BUFFA, Ester; ARROYO, Miguel González; NOSELLA, Paolo (Orgs.). Educação e cidadania: quem educa o cidadão? 14. ed. São Paulo: Cortez, 2007. 94 p.

CUSTÓDIO, Crislei de Oliveira. A pedagogia como discurso de normatização da infância em situação escolar. In: BOTO, Carlota; AQUINO, Julio Groppa. Democracia, escola e infância. São Paulo: FEEUSP, 2019, 210p. 
FERREIRA-DA-SILVA, Otavio Henrique. Educação Infantil em Betim (1958-2016). Rio de Janeiro: Synergia, 2016, 96 p.

FERREIRA-DA-SILVA, Otavio Henrique. Gestão democrática na educação infantil. Contagem: Escola Cidadã, 2020, 174 p.

FILGUEIRAS, Cristina Almeida Cunha. A creche comunitária na nebulosa da pobreza. Cadernos de Pesquisa. São Paulo, n. 88, p. 18-29, fev. 1994.

FREIRE, Paulo. Pedagogia da Autonomia: saberes necessários à prática educativa. 58. ed. São Paulo: Paz e Terra, 1996[2019], 143p.

HEILBORN, Maria Luiza; ARAÚJO, Leila; BARRETO, Andreia. Gestão de Políticas Públicas em Gênero e Raça III - Políticas Públicas e Raça. Rio de Janeiro: CEPESC; Brasília: SPM, 2010, 238 p.

LEWIS, Isaac Warden. Violência histórica na sociedade brasileira colonizada. Manaus: Editora Mundo Novo, 2019, 46p.

NOGUERA-RAMÍREZ, Ernesto. A escola e a educação: uma questão antropotécnica. In: BOTO, Carlota; AQUINO, Julio Groppa. Democracia, escola e infância. São Paulo: FEEUSP, 2019, 210p.

PRIORE, Mary Del. Apresentação. In: PRIORE, Mary Del (Org.). Histórica das crianças no Brasil. 7. ed. São Paulo: Contexto, 2018, 444p.

SANTIAGO, Flávio; FARIA, Ana Lúcia Goulart de. Para além do adultocetrismo: uma outra formação docente descolonizadora é preciso. Educação e Fronteiras Online. Dourados, v.5, n.13, p.72-85, jan-abr. 2015.

SOUZA, Jésse. (Não) reconhecimento e subcidadania, ou o que é "ser gente"?. Lua Nova. São Paulo, n. 59, p. 51-73, 2003.

\section{Como referenciar este artigo}

FERREIRA-DA-SILVA, O. H. Dos vestígios coloniais à descolonização da educação infantil. Revista on line de Política e Gestão Educacional, Araraquara, v. 25, n. 1, p. 311-325, jan./abr. 2021. e-ISSN:1519-9029. DOI: https://doi.org/10.22633/rpge.v25i1.14841

Submetido em: 25/03/2020

Revisões requeridas em: 13/08/2020

Aprovado em: $15 / 11 / 2020$

Publicado em: 02/01/2021 